\title{
An RNA molecule that specifically inhibits G-protein-coupled receptor kinase 2 in vitro
}

\author{
GÜNTER MAYER, ${ }^{1}$ BERNHARD WULFFEN, ${ }^{1}$ CHRISTIAN HUBER, ${ }^{2}$ JÖRG BROCKMANN, ${ }^{3}$ \\ BIRGIT FLICKE, ${ }^{4}$ LARS NEUMANN, ${ }^{4}$ DORIS HAFENBRADL, ${ }^{4}$ BERT M. KLEBL, ${ }^{4}$ \\ MARTIN J. LOHSE, ${ }^{3}$ CORNELIUS KRASEL, ${ }^{3,5}$ and MICHAEL BLIND ${ }^{2}$ \\ ${ }^{1}$ Life and Medical Sciences Bonn, Program Unit Chemical Biology, c/o Kekulé-Institute for Organic Chemistry and Biochemistry, \\ University of Bonn, 53121 Bonn, Germany \\ ${ }^{2}$ NascaCell Technologies AG, 81377 Munich, Germany \\ ${ }^{3}$ Institute of Pharmacology and Toxicology, University of Würzburg, 97078 Würzburg, Germany \\ ${ }^{4}$ GPC Biotech, 82152 Martinsried, Germany \\ ${ }^{5}$ School of Pharmacy, University of Reading, Whiteknights, Reading RG6 6AJ, United Kingdom
}

\begin{abstract}
G-protein-coupled receptors are desensitized by a two-step process. In a first step, G-protein-coupled receptor kinases (GRKs) phosphorylate agonist-activated receptors that subsequently bind to a second class of proteins, the arrestins. GRKs can be classified into three subfamilies, which have been implicated in various diseases. The physiological role(s) of GRKs have been difficult to study as selective inhibitors are not available. We have used SELEX (systematic evolution of ligands by exponential enrichment) to develop RNA aptamers that potently and selectively inhibit GRK2. This process has yielded an aptamer, C13, which bound to GRK2 with a high affinity and inhibited GRK2-catalyzed rhodopsin phosphorylation with an IC Fo of.1 $\mathrm{nM}$. Phosphorylation of rhodopsin catalyzed by GRK5 was also inhibited, albeit with 20 -fold lower potency (IC 50 of 79 nM). Furthermore, C13 reveals significant specificity, since almost no inhibitory activity was detectable testing it against a panel of 14 other kinases. The aptamer is two orders of magnitude more potent than the best GRK2 inhibitors described previously and shows high selectivity for the GRK family of protein kinases.
\end{abstract}

Keywords: in vitro selection; SELEX; aptamer; GRK2; kinase inhibitor

\section{INTRODUCTION}

G-protein-coupled receptors (GPCRs) are the most diverse family of receptors that transmit extracellular stimuli to the cell interior, thereby regulating various physiological processes. Upon agonist binding, GPCRs undergo conformational changes that are rapidly transmitted to heterotrimeric $G$ proteins that mediate the intracellular propagation of the signal. Subsequently, signal transduction through GPCRs is often modulated by receptor phosphorylation. Receptor phosphorylation occurs via various kinases, such as cAMP-

Reprint requests to: Günter Mayer, Life and Medical Sciences Bonn, Program Unit Chemical Biology, c/o Kekulé-Institute for Organic Chemistry and Biochemistry, University of Bonn, Gerhard-Domagk-Strasse 1, 53121 Bonn, Germany; e-mail: gmayer@uni-bonn.de; fax: +49-228734809; or Michael Blind, NascaCell Technologies AG, Max-LebschePlatz 31, 81377 Munich, Germany; e-mail: m.blind@nascacell.de; fax: $+49-89-54727222$.

Article published online ahead of print. Article and publication date are at http://www.rnajournal.org/cgi/doi/10.1261/rna.821908. dependent kinase (PKA), protein kinase C, calmodulindependent kinase, and most importantly G-protein-coupled receptor kinases (GRKs) (Premont et al. 1995; Mayor et al. 1998; Premont and Gainetdinov 2007; Ribas et al. 2007). G-protein-coupled receptor kinases represent a protein family comprising seven distinct members that can be grouped into three subfamilies (Lohse et al. 1996; Oppermann et al. 1996; Pitcher et al. 1998; Premont et al. 1999). The GRK2 subfamily consists of GRK2 and GRK3, both of which are expressed throughout the body (Peppel et al. 1997). These kinases require interaction with G-protein $\beta \gamma\left(G_{\beta \gamma}\right)$ subunits for membrane binding and activation, and the X-ray structure of GRK2 in complex with $G$ proteins was solved recently (Tesmer et al. 2005). A second GRK subfamily comprises the isoforms GRK4, -5, and -6 , of which GRK5 is considered the ubiquitously expressed prototype. In contrast to the GRK2 family, the GRK5 family members do not interact with $G_{\beta \gamma}$ subunits (Kunapuli and Benovic 1993). GRK1 and -7, finally, occur only in the eye and are involved in the dampening of light 
responses. GRK-mediated phosphorylation of GPCRs and subsequent binding of $\beta$-arrestins serves several functions. It terminates classical, G-protein-mediated signaling (Lohse 1993), it initiates receptor internalization (Marchese et al. 2003), and it triggers "nonclassical" signaling such as activation of MAP kinases (Lefkowitz and Shenoy 2005).

Decreased GRK2 expression has been associated with immunological pathologies (Lombardi et al. 2002; Vroon et al. 2004), whereas the increased GRK2 expression is associated with a number of diseases, for example, in heart failure and hypertension (Ungerer et al. 1993, 1994; Koch et al. 1995; Rockman et al. 2002; Hata and Koch 2003), resulting in impaired transmission of signals via several GPCRs, such as the $\beta_{1}$-adrenergic receptor. It has been hypothesized that interfering with GRK2 function might be beneficial in heart failure since increased GRK2 expression can be observed before the onset of the disease. In support of this hypothesis, it was demonstrated that transgenic cardiac expression of the C terminus of GRK2 (which scavenges $G_{\beta \gamma}$ subunits) leads to reduced GRK activity, increased $\beta$-adrenergic signaling, and partial restoration of heart function in several murine models of heart failure (Petrofski and Koch 2003; Lymperopoulos et al. 2007). Recently, GRK2 has also been found to be involved in cross-talk to other signaling pathways, affecting their signal transmission, including insulin signaling (Usui et al. 2004, 2005) and MAP kinase signaling (Lorenz et al. 2003; Peregrin et al. 2006). These data underline that specific and potent inhibitors of the GRK2 kinase will represent promising molecules as tools for the characterization of GRK2 function and potentially also for the development of new treatments for severe diseases, such as heart failure and diabetes (Iaccarino and Koch 1999; Kenski et al. 2005; Hansen et al. 2006).

RNA aptamers can be identified by in vitro selection processes, also termed SELEX (systematic evolution of ligands by exponential enrichment), for various target molecules, including small molecules, peptides, proteins, and even living cells (Ellington and Szostak 1990; Tuerk and Gold 1990; Wilson and Szostak 1999). Furthermore, aptamers have been shown to be potent and specific inhibitors of several protein classes both in the extracellular and intracellular environment (Famulok and Mayer 2005). Once an inhibitory aptamer has been identified and validated, the chemical information stored in the aptamer might be converted into a small druglike molecule with the inherited properties of the parent aptamer (Hartig et al. 2002; Hafner et al. 2006). By this means the versatility of in vitro selection can be combined with the ease of applying small molecules to cells or living organisms, which can be applied to investigate protein function and further serve as leads for therapeutic drug development (Burgstaller et al. 2002a,b; Famulok and Mayer 2005). We applied in vitro selection to identify a highly specific RNA aptamer that binds to GRK2 and inhibits its kinase function. This RNA aptamer represents the most potent inhibitor of GRK2 activity reported so far. More importantly, the aptamer possesses a high specificity for GRK function, and thus it might allow the precise functional characterization of GRK2 both in cell culture and in vivo. Furthermore, this aptamer might represent a starting point for the development of small molecules that specifically target GRK2.

\section{RESULTS}

\section{In vitro selection}

We applied a structurally constrained RNA library for the in vitro selection procedure. RNA libraries with structural constraints have the advantage that successfully enriched aptamers that maintain the preset secondary structure can be easily truncated, engineered, and adapted to various application formats. Such RNA libraries comprising a G-quadruplex biased structure or random regions flanked by stable hairpin structures were described previously and successfully used for the identification of RNA aptamers (Hamm 1996; Davis and Szostak 2002). We followed a different approach and designed a RNA library that has a stable stem structure 13 nucleotides (nt) in length, flanked by two restriction sites (5'-Pst1 and a $3^{\prime}$-HindII) and additional primer binding sites that allow reverse transcription and PCR amplification (Fig. 1A). The 13-nt stem structure starts with two consecutive G-U base pairs, and for further reduction of the stability of the stem we included a central A-A mismatch. These modifications were thought to reduce reverse transcriptase pausing at the beginning of the stem structure and thus allow efficient reverse transcription of the appropriate RNA molecules compared with completely Watson-Crick base-paired stems. The region comprising 20 random nucleotides resides as loop structure on top of the stem motif (Fig. 1A). By this means the stem represents a RNA clamp segment that separates the random region from the primer binding and restriction sites of the entire RNA molecule. We anticipated that successfully enriched RNA aptamers might be readily truncated just by removing the restriction and primer binding sites while maintaining their secondary structure folding. This RNA library was subjected to an automated in vitro selection process resulting in RNA aptamers that specifically bind and inhibit GRK2. GRK2 was expressed in Sf 9 cells by infection with a recombinant baculovirus and purified by affinity chromatography using heparin sepharose columns followed by ion exchange chromatography (Kim et al. 1993). The purity of the protein was determined to be greater than $95 \%$ by SDS-PAGE analysis. Aliquots of purified GRK2 were stored at $-80^{\circ} \mathrm{C}$ (data not shown). Prior to in vitro selection GRK2 was biotinylated using a fivefold molar excess of NHS-LC-sulfobiotin in the presence of ATP and $\mathrm{Mg}^{2+}$ ions. ATP and $\mathrm{Mg}^{2+}$ ions were included in the biotinylation step to protect 
A

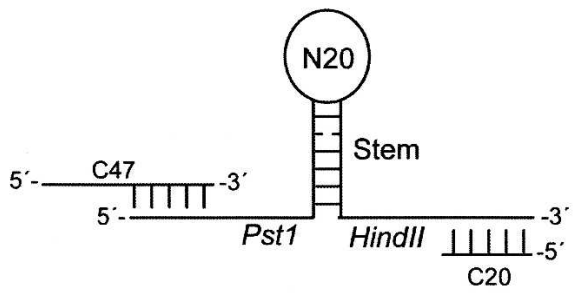

B

C

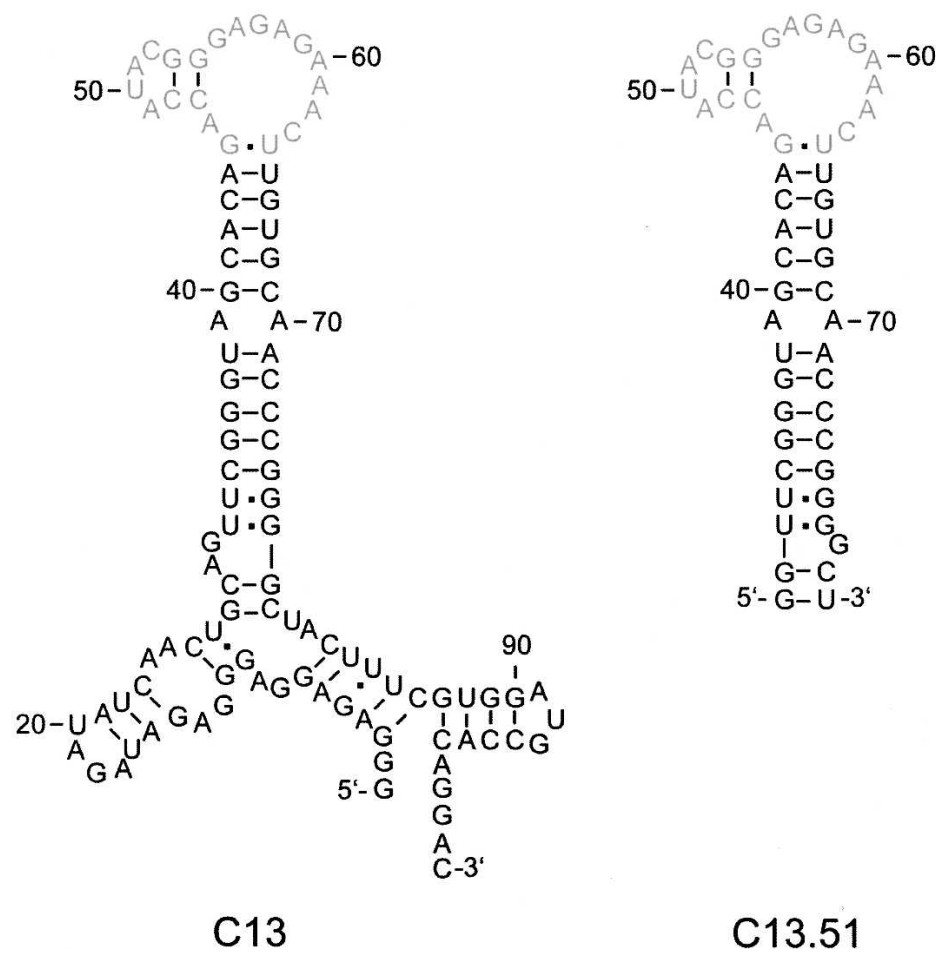

FIGURE 1. In vitro selection using a structurally constrained RNA library. (A) Design of the constrained RNA library comprising a 13-nt stem structure with a central A-A mismatch, PstI and HindII restriction sites, and a 20-nt (N20) random region. Oligodeoxynucleotides used as primer molecules for reverse transcription and PCR amplification are designated as $\mathrm{C} 47$ and C20 and their binding sites are indicated. (B) Sequences of the selected RNA molecules without the constant regions of the primer binding sites. Pst1, Stem, N20, and HindII indicate the original assignation of the sequence part in the starting library. (C) Proposed secondary structure model of the RNA aptamer C13 (left) and the supposed truncated variant C13.51 (right). Nucleotides in gray represent the selected sequence. the invariant lysine K220 residue in the catalytic core of the kinase domain from being modified and thus unavailable as a putative aptamer target site. The biotinylated protein was subsequently coupled to streptavidin-coated magnetic particles, and the derivatized beads were directly used during the selection process. After 12 selection cycles the enriched RNA library was analyzed for GRK2 binding, and increased affinity of the enriched RNA library compared to the starting library was observed (data not shown). The enriched RNA library was cloned and the sequences of 18 monoclones were determined (Fig. 1B). The sequences C7 and $\mathrm{C} 9$ resemble the structural features of the constrained RNA library. All other sequences were found to contain various mutations, such as missing the $3^{\prime}$ restriction site $(\mathrm{C} 1, \mathrm{C} 2, \mathrm{C} 12)$ or deletions and mutations of nucleotides within the $3^{\prime}$ part of the 13-nt stem region (C3 to $\mathrm{C} 5$ ). Remarkably, none of the sequences revealed mutations within the $5^{\prime}$ restriction site or at the $5^{\prime}$ part of the 13-nt stem region.

\section{The RNA aptamer C13 binds GRK2 with high affinity and specificity}

We used filter retention assays to analyze the binding properties of individual RNA aptamers (data not shown). Among them the RNA aptamer C13 was observed to bind to GRK2 with the highest affinity, and a dissociation constant value of $78.2 \mathrm{nM} \pm 2.6 \mathrm{nM}$ (Table 1; Supplemental Fig. SF1A) was determined. Furthermore, filter retention assays using the Ser/Thr kinases cAMP-dependent kinase (PKA), protein kinase $\mathrm{C}$ (isoform $\mathrm{PKC} \varepsilon$ ), and the MAP kinase Erk-2 revealed that the interaction of C13 with GRK2 is highly specific (Table 1; Supplemental Figs. SF1A, SF1B). C13 contains almost all features of the structurally constrained RNA library (Fig. 1B). However, the sequence of the HindII restriction site was mutated and reads GCTAC instead of GTTAAC. Most importantly, the 13-nt stem region does not carry any mutations and, according to our design 
TABLE 1. Dissociation constant values of the RNA aptamers C13 and $\mathrm{C} 13.51$

\begin{tabular}{lrccc}
\hline & \multicolumn{4}{c}{$K_{D}(\mathrm{nM})$} \\
\cline { 2 - 5 } Aptamer & \multicolumn{1}{c}{ GRK2 } & C-terminal & Erk-2 & PKA \\
\hline C13 & $78.2 \pm 2.6$ & n.d. & $>5000$ & $>5000$ \\
C13.51 & $101.2 \pm 7.2$ & - & - & - \\
\hline
\end{tabular}

(GRK2) G-protein coupled receptor kinase; (C-terminal) C-terminal domain of GRK2; (Erk-2) extracellular regulated kinase-2; (PKA) cAMP-dependent protein kinase A. (n.d.) not detectable; (-) not determined.

strategy, the RNA aptamer should be easily truncated by excluding the primer binding and the restrictions sites, respectively. We thus produced a truncated variant of $\mathrm{C} 13$ consisting of $51 \mathrm{nt}$, termed C13.51 (Fig. 1C), and analyzed its binding behavior in filter retention assays (Table 1). As expected, the truncated variant $\mathrm{C} 13.51$ also binds with high affinity to GRK2, and a dissociation constant value of $101.2 \mathrm{nM} \pm 7.2 \mathrm{nM}$ was observed, essentially matching the $K_{D}$ of the full length aptamer (Table 1).

\section{C13 reflects the structural constraints of the RNA library}

Having demonstrated that $\mathrm{C} 13$ can be easily truncated according to our design strategy, we set out to further prove the secondary structure of C13. Therefore, we employed chemical probing to analyze whether the stem and the selected region of $\mathrm{C} 13$ can be resolved. As illustrated in Figure 2, the secondary structure of $\mathrm{C} 13$ is basically consistent with the structural constraints of our design strategy. Apart from the modifications of A39 and A70, which were thought to form a mismatch in the putative stem region, almost no other nucleotides within the stem region were modified during incubation with dimethlysulfate (DMS), kethoxal or 1-cyclohexyl-3-(2morpholinoethyl)-carbodiimide (CMCT) (Fig. 2A). With the exception of nucleotides G53, G54, C47, and C48, all nucleobases of the initial random region were efficiently modified by the appropriate chemical. This suggests that the nucleotides G53, G54, C47, and C48 form a short basepaired segment within the selected region (Fig. 2B). The importance of the formation of the 13-nt clamp structure of the aptamer is further supported by the fact that the interaction of $\mathrm{C} 13$ with GRK2 strictly depends on the concentration of monovalent cations such as $\mathrm{K}^{+}$(data not shown) and $\mathrm{Na}^{+}$(Supplemental Fig. SF3).

\section{The aptamer targets the kinase domain of GRK2}

Next, we determined which GRK2 subdomain is recognized by $\mathrm{C} 13$. We therefore performed filter retention assays using a truncated GRK2 protein comprising solely the Cterminal $\mathrm{PH}$ domain of GRK2, which is responsible for interacting with the $\mathrm{G}_{\beta \gamma}$ subunits of $\mathrm{G}$ proteins and a $\mathrm{N}$ terminal construct reflecting the RH domain of GRK2 (Fig. 3A). Figure 3B clearly shows that the $\mathrm{C} 13$ does interact neither with the C-terminal domain nor with the $\mathrm{N}$ terminal domain of GRK2, indicating that the binding region of $\mathrm{C} 13$ is located in the kinase domain. Immunoblot analysis was applied to verify whether the aptamer also interacts with endogenous GRK2, isolated from HEK 293 cells. Therefore, biotinylated variants of the $\mathrm{C} 13$ or a control RNA were coupled to streptavidin-coated magnetic beads. These beads were used as affinity matrix, and after incubation with HEK cell lysate specifically bound endogenous GRK2 was analyzed by SDS-PAGE, followed by Western blot and visualization with a polyclonal antiGRK2 antibody. As depicted in Figure 3C, the C13 aptamer interacts with endogenous GRK2 whereas no interaction could be monitored using a control RNA. To further nail down the interaction domain of C13 with the GRK2 protein, we used the alkaloid staurosporine, an ATP analog, as competitor to further narrow down the aptamer's binding site. Staurosporine was originally isolated from Streptomyces staurosporeus and is known to bind and to inhibit the kinase activity of various Ser/Thr-kinases including GRK2 (Penn et al. 1999). In addition we included the

A B
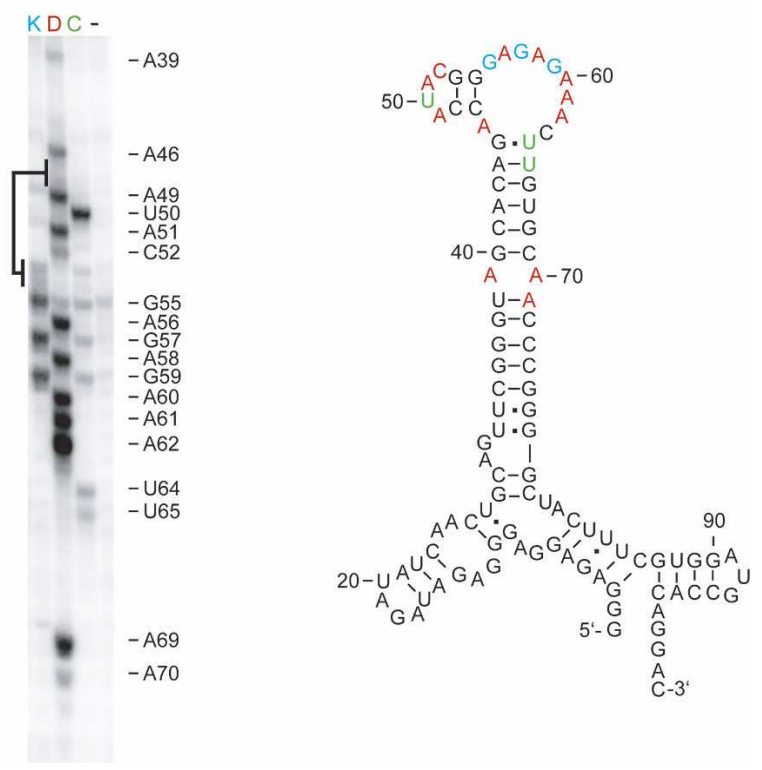

FIGURE 2. Secondary structure analysis of $\mathrm{C} 13$ by chemical probing. (A) Chemical probing of the RNA aptamer C13 $(1 \mu \mathrm{g} / \mu \mathrm{L})$. (K) Kethoxal; (D) DMS; (C) CMCT; (-) control lane without chemical. The black lines indicate possible base-pairing of $\mathrm{C} 47$ and $\mathrm{C} 48$ with G53 and G54 as depicted in B. (B) Secondary structure model of the RNA aptamer C13. Nucleobases that were modified by the appropriate chemical are indicated by color. (Blue) Kethoxal; (Red) DMS; (Green) CMCT. 
A

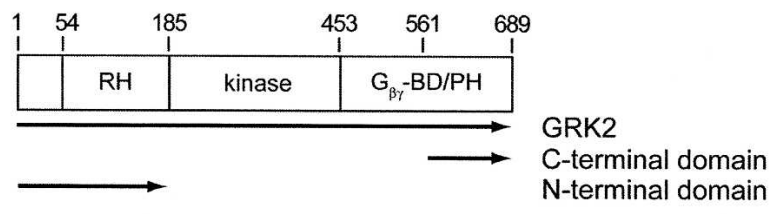

B

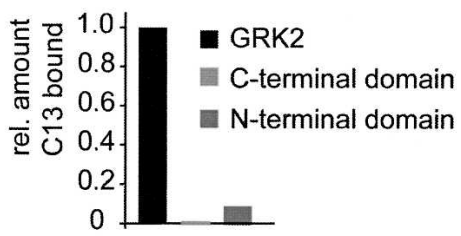

D

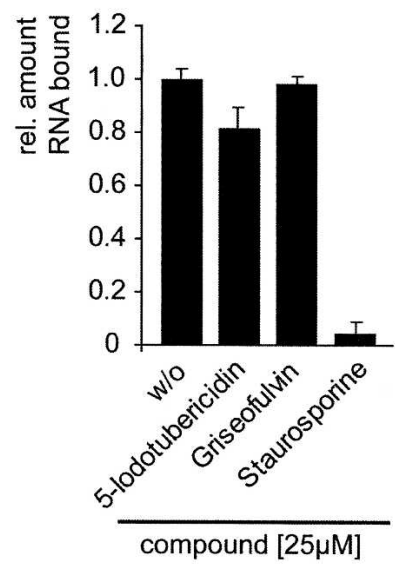

E

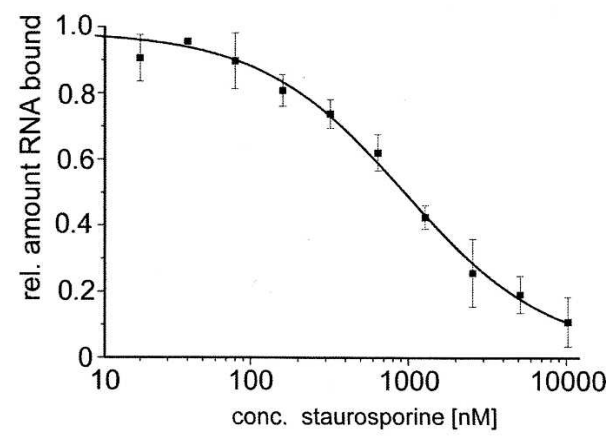

$\mathbf{F}$

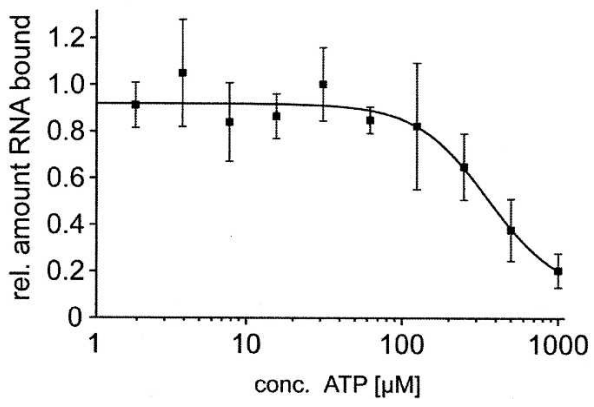

FIGURE 3. C13 interacts with the kinase domain of GRK2 as well as with endogenous GRK2. (A) Schematic representation of human GRK2. Arrows indicate the length of either the fulllength GRK2, the N-terminal domain $\left(\mathrm{GRK}^{1-185}\right)$, or the C-terminal domain (GRK2 ${ }^{561-689}$ ) used in this study. (B) Filter retention analysis of the relative amount of radioactively labeled C13 RNA bound after incubation with the C-terminal domain $(500 \mathrm{nM})$ or N-terminal domain $(500 \mathrm{nM})$ and filtration through nitrocellulose membranes. The amount which was bound to GRK2 (500 nM) was set to 1. (C) C13 interacts with endogenous GRK2. Biotinylated $\mathrm{C} 13$ or control RNA was coupled to streptavidin-coated magnetic beads and used as affinity matrix to pull down endogenous GRK2 from HEK 293 cell lysates. Affinity matrix: (left lane) control RNA; (middle lane) C13; (right lane) recombinant GRK2 (rGRK2) (240 ng) directly loaded on SDS-PAGE as size and antibody control. Visualization of endogenous and recombinant GRK2 was achieved by Western blot analysis using the specific anti-GRK2 polyclonal antibody C15 for immunostaining and ECL. (D) Competition of C13 with staurosporine, griseofulvin, and 5-iodotubercidin ( $25 \mu \mathrm{M}$ each) for GRK2 binding. Amount of bound radioactively labeled C13 in the absence (w/o) compounds to GRK2 (150 nM) was set to 1. (E) Concentration-dependent competition of C13 binding to GRK2 with staurosporine. GRK2 concentration was as in $C$. $(F)$ Concentration-dependent competition of $\mathrm{C} 13$ binding to GRK2 with ATP. GRK2 concentration was as in $C$.

synthetic adenosine derivative 5-iodotubericidin in the competition experiments. This compound is known to inhibit other Ser/Thr kinases such as the MAP kinase Erk-2 (Fox et al. 1998). As a control compound, we used griseofulvin, an antifungal drug that binds to tubulin. For competition experiments we incubated radioactively labeled C13 with constant concentrations of GRK2 (150 nM) in the presence of staurosporine, 5-iodotubericidin, or griseofulvin at concentrations of $25 \mu \mathrm{M}$. After incubation the samples were filtered, washed with buffer, and the amount of aptamer retained was quantified by phosphorimaging. As shown in Figure 3D, staurosporine effectively competed the binding of the aptamer to GRK2 whereas 5-iodotubericidin was less potent, in accordance with data from the literature (Fox et al. 1998; Penn et al. 1999). As expected, griseofulvin had no effect on aptamer binding to GRK2. The competition of staurosporine was further shown to be concentration dependent, and an $\mathrm{IC}_{50}$ value of $0.95 \mu \mathrm{M} \pm 0.17 \mu \mathrm{M}$ was determined (Fig. 3E). In agreement with these data, competition of aptamer binding to GRK2 with ATP was also observed (Fig. 3F). Half maximal inhibition was detected at an ATP concentration of $452 \mu \mathrm{M}$ which is 7.5 -fold above the reported $K_{M}$ value of $60.8 \mu \mathrm{M}$ of ATP and GRK2 (Kim et al. 1993; Knight and Shokat 2005). No competition of the aptamer GRK2 interaction with UTP was detectable (data not shown). In summary, our data indicate that the binding of C13 to GRK2 is mediated via the kinase domain of GRK2, most probably mediated inter alia via the ATP-binding pocket.

\section{C13 is a potent inhibitor of GRK2 kinase activity}

Since the RNA aptamer C13 competes with the ATP analog staurosporine for GRK2 binding it is likely that the aptamer binds to the kinase domain of GRK2. Consequently, we investigated the inhibitory potential of C13. GRK2 kinase activity assays were performed 
using bovine rhodopsin as GRK2 substrate (Winstel et al. 1996). Rhodopsin can be activated by light as an exogenous trigger signal, and GRK2 activity was further induced by exogenously added $\mathrm{G}_{\beta \gamma}$ subunits. GRK2 kinase activity was strongly inhibited in the presence of increasing concentrations of $\mathrm{C} 13$ whereas the diverse RNA library had almost no effect at concentrations as high as $5 \mu \mathrm{M}$ (Fig. 4A; Supplemental Fig. SF4A). The $\mathrm{IC}_{50}$ value was determined to be $4.1 \mathrm{nM} \pm 1.2 \mathrm{nM}$ (Fig. 4B; Supplemental Fig. SF4B). Thus, the aptamer $\mathrm{C} 13$ represents the most potent inhibitor of the GRK2 kinase activity reported so far.

Next we determined the potential of the aptamer to inhibit other kinases. To analyze the specificity of $\mathrm{C} 13$ for members of the GRK family, we determined the kinase activity of GRK5 in the presence of increasing concentrations of C13. As shown in Figure 4C, C13 also inhibits the kinase activity of GRK5 in a concentration-dependent manner with an $\mathrm{IC}_{50}$ value of $79.4 \mathrm{nM} \pm 20.4 \mathrm{nM}$. However, this value is more than one order of magnitude greater than the corresponding $\mathrm{IC}_{50}$ value obtained in the GRK2 inhibition assay and indicates that the aptamer possesses a significant specificity within the GRK family. Furthermore, we analyzed the effect of C13 on the phosphorylation activity of several other kinases that belong to distinct kinase groups, classified previously by Manning et al. (2002). We included kinases from the TK, the TKL, the AGC, and the CMGC group. The assays were performed using peptides, poly $(\mathrm{E}, \mathrm{Y}) 4: 1$ or myelin basic protein as substrates (Supplemental Table ST1), and data analysis was achieved by scintillation counting. In this assay format the $\mathrm{IC}_{50}$ value of $\mathrm{C} 13$ toward GRK2 kinase activity was determined to be $2 \mathrm{nM} \pm 0.3 \mathrm{nM}$ (data not shown), which is slightly improved compared to the value obtained using rhodopsin as a substrate (Fig. 4B). C13 virtually abolished GRK2 activity at concentrations of $20 \mathrm{nM}$, which is 10 -fold above the determined $\mathrm{IC}_{50}$ value in this assay format (Fig. 4D), whereas it had little effect on the kinase activity of most of the other kinases. However, some kinases, such as c-Met and Erk1, exhibited slightly enhanced kinase activities in the presence of the RNA aptamer. The kinase activity of GSK3beta kinase from the CMGC group and the TK group kinases EGFR and Abl, respectively, were found to be slightly inhibited by C13. Taken together the data show that the RNA aptamer C13 is a very specific and potent antagonist of GRK2 kinase function.

\section{DISCUSSION}

In this study, we describe the identification and characterization of an RNA aptamer that targets the human Gprotein-coupled receptor kinase 2 (GRK2). We employed an automated in vitro selection procedure (Cox and Ellington 2001; Cox et al. 2002) for the enrichment of the RNA ligand and isolated an aptamer, namely C13, which was shown to bind to the kinase domain of GRK2 with high affinity. We applied a RNA library that comprised a structurally predefined region for the in vitro selection. Similar libraries have been successfully used by others targeting proteins or small molecules (Giver et al. 1993; Hamm 1996; Hamm et al. 1997; Hermann and Patel 2000; Davis and Szostak 2002). Here we embedded a 20-nt random sequence as part of the constraint. We defined

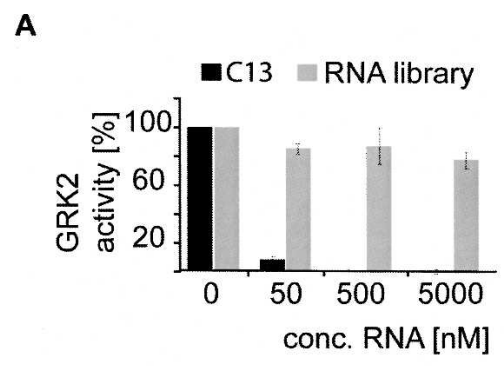

B

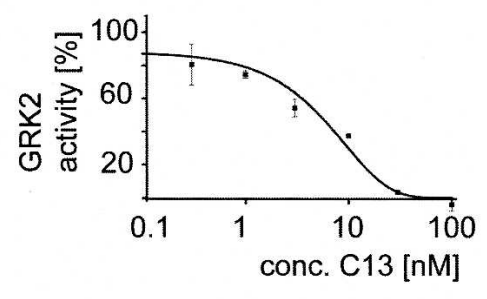

C

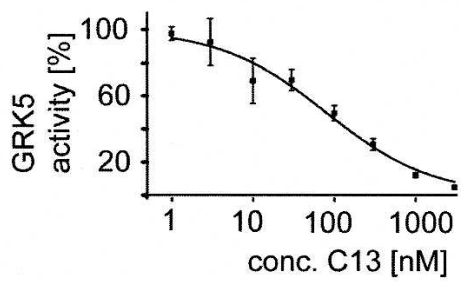

D

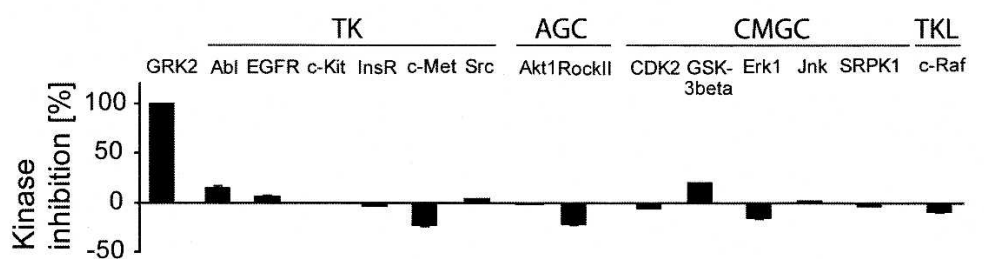

FIGURE 4. Inhibition of GRK2 kinase activity by C13. (A) Phosphorylation of rhodopsin by GRK2 in the presence of increasing concentrations of C13 or the RNA library. $(B)$ Concentration dependency of inhibition of GRK2-mediated rhodopsin phosphorylation by C13. (C) Concentration dependency of inhibition of GRK5-mediated rhodopsin phosphorylation by C13. (D) Inhibition of distinct kinases belonging to the TK (tyrosine kinase), TKL (tyrosine kinase-like), AGC (containing PKA, PKG, PKC families), and CMCG (containing CDK, MAPK, GSK3, CLK families) groups defined by Manning et al. (2002) by C13 (20 nM). 
two 13-nt regions that can base pair and thus form a stem structure that flanks the 20-nt random region. Thus, the stem structure forms a clamp that holds together the $5^{\prime}$ and $3^{\prime}$ ends of the RNA molecules (Fig. 1A). By this means the random region can be functionally separated from the restriction and primer binding sites and thus enables straightforward truncation of a resulting aptamer by design (Fig. 1C; Table 1). The aptamer $\mathrm{C} 13$ reflects this predefined structural stem motif (Figs. 1B, 2). Chemical probing as well as truncation of the aptamer showed that the overall folding of the aptamer reflects the secondary structure that was preset by our design strategy (Fig. 2A). We demonstrated that a combination of random regions as short as $20 \mathrm{nt}$ with structural constraint motifs can be employed for the successful identification of RNA aptamers that target a protein kinase. These aptamers can be readily truncated as shown in this study (Fig. 1; Table 1), engineered and adapted to downstream applications. However, sequencing of the enriched library also revealed that the stem structure and adjacent restriction sites that were not part of the primer binding regions were mutated quite frequently (Fig. 1B). For future applications of such libraries primer oligodeoxynucleotides might be employed that pair within the stem sequences, thus maintaining proper sequence identity and avoiding mutations within these regions (Hamm 1996).

The aptamer competes with ATP and the alkaloid staurosporine for GRK2 binding (Fig. 3D-F). This suggests that the aptamer binds to the catalytic domain. Indeed, no binding was observed to the $\mathrm{N}$ - and C-terminal domains of GRK2 (GRK ${ }^{1-185}$ and GRK2 ${ }^{561-689}$, respectively) (Fig. 3B). The aptamer does not act by competing with $G_{\beta \gamma}$, as $G_{\beta \gamma^{-}}$ independent kinase activity is also inhibited. Competition experiments with ATP and staurosporine indicate that the aptamer presumably interacts with residues that reside within the ATP-binding site of GRK2 (Fig. 3D-F). Remarkably, we could also demonstrate that the aptamer also interacts with endogenous GRK2 isolated from HEK 293 cells (Fig. 3C), thus underlining the feasibility of the aptamer being used in cellular assays as GRK2 inhibitor in further studies.

Importantly, it was shown that aptamer $\mathrm{C} 13$ is the most potent GRK2 inhibitor described to date. Half-maximal inhibition was observed at concentrations as low as $4 \mathrm{nM}$ in the rhodopsin phosphorylation assay and $2 \mathrm{nM}$ in the peptide phosphorylation assay, whereas a dissociation constant of $78 \mathrm{nM}$ was determined by filter retention analysis. This difference of one order of magnitude might be explained by differences in the setup of both assay systems. In particular, it might be caused by misfolding of the GRK on the nitrocellulose filters during the binding assay, while the activity assay was carried out in solution. Another possibility might be reflected by batch to batch variations of the GRK2 protein preparations, resulting in different ratios of active kinase vs. inactive kinase, and thereby influencing filter retention assays in which these two portions can hardly be distinguished. The higher affinity of the aptamer in the kinase assays could also be caused by a conformational change induced by the aptamer binding close to the ATP binding site, which might have an impact on the binding of ATP. Such a finding is not without precedence as well when dealing with active site competitors of the ATP binding site.

The aptamer showed exceptional specificity against a panel of kinases belonging to distinct kinase groups (Manning et al. 2002) despite its apparent interaction with the ATP site (Fig. 4D). Only 3 out of 14 examined kinases revealed negligible inhibition of their kinase function in the presence of $20 \mathrm{nM}$ aptamer. Furthermore, the aptamer showed GRK subtype selectivity, as half-maximal inhibition of GRK5 was observed at concentrations that were nearly 20-fold greater compared to inhibition of GRK2 (Fig. 4C).

Previously, aptamers have been isolated that target either PKC $\beta$ or Erk-2 MAP kinase and both aptamers have been shown to inhibit the kinase activity of their related target proteins (Conrad et al. 1994; Seiwert et al. 2000). The specificities of both reported aptamers were analyzed in respect of members of the same protein family. In this study, we tried to address this selectivity question by investigating the specificity of the anti-GRK2 aptamer against individual members of four different kinase groups (TK, TKL, AGC, CMGC groups according to Manning et al. 2002).

Heparin, peptides, and the synthetic compound suramin have been described as potential GRK2 inhibitors (Kim et al. 1993; Hasbi et al. 2000; Kassack et al. 2000; Winstel et al. 2005). However, heparin, which inhibits GRK2 at low nanomolar concentrations is highly charged and can only be used when it has direct access to GRKs (Lohse et al. 1989). And for the other inhibitors, the reported $\mathrm{IC}_{50}$ values were in the submicromolar and higher micromolar range. Additionally, suramin has a high intrinsic cytotoxic potential and thus it is not useful for specifically interfering with GRK2 function either in cell-based assays or in in vivo scenarios. Shokat and coworkers recently reported a chemical genetic approach for obtaining potent GRK2 inhibitors. They introduced defined mutations in the kinase domain of GRK2 that renders the protein susceptible for a known kinase inhibitor, namely 1-naphtyl-PP1 (Kenski et al. 2005). Taken together these reports indicate that there is a constant need for specific and potent kinase inhibitors, and we believe that the aptamer described in this study might be beneficial for the functional interference and characterization of GRK2.

In summary, we have identified a novel RNA-based inhibitor of GRK2 function in vitro. The described aptamer represents the most potent inhibitor of GRK2 kinase function reported so far. The aptamer possesses high specificity toward GRK2 as compared to other kinases and thus represents a promising starting point for the 
functional interference and analysis of endogenous GRK2 function inside cells and living organisms. For example the aptamer can be either directly transfected into cells or expressed from plasmids that encode the aptamer sequence under certain promoter elements (Mayer et al. 2001; Theis et al. 2004; Famulok and Mayer 2005). Recent studies demonstrated that aptamers can be converted into small molecule inhibitors using so-called aptamer-displacement assays (Hafner et al. 2006). It has been shown that these small molecules inherit the properties of the parent aptamer and can be easily applied to cell culture and animal models systems, which is at least in the latter case hard to obtain with nucleic acid based inhibitors. It would be of outstanding interest to see whether the specificity of the aptamer can be transferred into a small molecule with identical functional properties.

\section{MATERIAL AND METHODS}

\section{DNA oligodeoxynucleotides and the preparation of the RNA library}

The library C2 5'-GGGAGAGGAGGGAGATAGATATCAACTG CAGTTCGGGTAGCACAN20TGTGCAACCCGGGTTAACTTTTC GTGGATGCCACAGGAC-3' was purchased from Metabion and amplified using the primer pair $5^{\prime}-\mathrm{C}-47$ (5'-AATTCTAATAC GACTCACTATAGGGAGAGGAGGGAGATAGATATCAA-3') and $3^{\prime}$-C-20 (5'-GTCCTGTGGCATCCACGAAA-3'). The dsDNA was used as a template for in vitro transcription followed by RNA purification employing polyacrylamide gel electrophoresis and crush and soak work up. Five hundred picomoles of the purified RNA were used as starting library in the first selection cycle.

\section{Expression and purification of GRK2, GRK5, the $\mathrm{N}$-terminal domain $\mathrm{GRK}^{1-185}$, and the C-terminal domain GRK $^{561-689}$}

Human GRK2 and GRK5 were expressed in Sf9 cells using recombinant baculoviruses and purified by SP-Sepharose and heparin-Sepharose as described by Kim et al. (1993). The Cterminal domain of GRK2, GRK ${ }^{561-689}$, and the N-terminal domain of GRK2, GRK2 $2^{1-185}$, were expressed in Escherichia coli as glutathione $S$-transferase (GST) fusion protein and purified by affinity chromatography on glutathione-Sepharose $4 \mathrm{~B}$ as described (Winstel et al. 1996; Eichmann et al. 2003).

\section{In vitro selection}

In vitro selection was performed on an automated platform as described elsewhere (Cox and Ellington 2001; Cox et al. 2002) with the following modifications. In brief, the incubation of the target protein with the RNA library was done in PBS ( $\mathrm{pH} 7.4$ ) and $3 \mathrm{mM} \mathrm{MgCl}_{2}$ at $37^{\circ} \mathrm{C}$ for $30 \mathrm{~min}$. GRK2 $(1 \mu \mathrm{g} / \mu \mathrm{L})$ was biotinylated with sulfo-NHS-LC biotin (Pierce) according to the manufacturer's protocol in the presence of $10 \mathrm{mM} \mathrm{MgCl}_{2}$ and $100 \mu \mathrm{M}$ ATP to avoid modification of the K220 residues within the catalytic core of GRK2. The nonreacted biotin-esters were removed from the protein solution by gel filtration using Micro
Biospin P6 columns (BioRad). The biotinylated protein was subsequently coupled to $5 \mathrm{mg}$ streptavidin beads (Dynal) and the resulting beads ( $267 \mu \mathrm{g}$ per cycle) were directly used for the selection process.

\section{Determination of $K_{D}$ values and small molecule competition experiments}

Labeled RNA was obtained by in vitro transcription using $\alpha$ $\left({ }^{32} \mathrm{P}\right)$-GTP and purification of RNA was done using the Nucleotide removal kit (Qiagen) according to the manufacturer's protocol. Every transcribed RNA molecule was analyzed on a polyacrylamide gel for integrity. For measuring protein-RNA interactions, radioactively labeled RNA was incubated with increasing concentrations of protein in binding buffer $\left(\mathrm{PBS} / 3 \mathrm{mM} \mathrm{MgCl}_{2}\right)$ at $37^{\circ} \mathrm{C}$ for $30 \mathrm{~min}$ and then passed through nitrocellulose $(0.45 \mu \mathrm{m}$, Schleicher \& Schuell). Subsequently, the membranes were washed with $1 \mathrm{~mL}$ binding buffer and dried. RNA retained on the membranes was quantified with a phosphorimager (FLA 5000, Fuji). Competition experiments with staurosporine, griseofulvin, and iodotubericidin were accomplished as follows: $150 \mathrm{nM}$ GRK2 was incubated as above in binding buffer with a constant amount of radioactively labeled RNA either in the absence or presence of $25 \mu \mathrm{M}$ of the indicated compounds or increasing concentrations of staurosporine or ATP. After incubation the samples were passed through nitrocellulose $(0.45 \mu \mathrm{m}$, Schleicher \& Schuell $)$ and further processed as described above. PKC $\varepsilon$ was purchased from Upstate, PKA was obtained from Sigma-Aldrich, and Erk-2 was expressed as His-tag fusion protein and purified using Ni-NTA chromatography according to the manufacturer's protocol (Qiagen).

\section{Chemical probing of C13}

Chemical probing was performed as described previously (Rentmeister et al. 2007). Modification with DMS or kethoxal: In a final volume of $10 \mu \mathrm{L}$, RNA $(0.2 \mu \mathrm{g} / \mu \mathrm{L})$ was incubated in $50 \mathrm{mM}$ HEPES ( $\mathrm{pH} \mathrm{7.8),} 100 \mathrm{mM} \mathrm{KCl}, 10 \mathrm{mM} \mathrm{MgCl}_{2}$ at $37^{\circ} \mathrm{C}$ for $30 \mathrm{~min}$. Then, $1 \mu \mathrm{L}$ of a $600 \mathrm{mM}$ solution of DMS in ethanol or $200 \mathrm{mM}$ kethoxal (ICN) in water, respectively, was added, mixed, and incubated $20 \mathrm{~min}$ at $37^{\circ} \mathrm{C}$. After precipitation, $5^{\prime}$-end-labeled primer was annealed and primer extension performed. Modification with CMCT: In a final volume of $10 \mu \mathrm{L}$, RNA $(0.2 \mu \mathrm{g} / \mu \mathrm{L})$ was incubated in $50 \mathrm{mM}$ potassium borate $(\mathrm{pH} 8.0), 100 \mathrm{mM} \mathrm{KCl}$, $10 \mathrm{mM} \mathrm{MgCl}_{2}$ at $37^{\circ} \mathrm{C}$ for $30 \mathrm{~min}$. Then $1 \mu \mathrm{L}$ of a $200 \mathrm{mM}$ solution of CMCT in water was added, mixed, and incubated $20 \mathrm{~min}$ at $37^{\circ} \mathrm{C}$. After precipitation, $5^{\prime}$-end-labeled primer was annealed and primer extension performed. In a $20-\mu \mathrm{L}$ reaction, $0.2 \mu \mathrm{g}$ RNA in $50 \mathrm{mM}$ Tris- $\mathrm{HCl}(\mathrm{pH} 8.3), 75 \mathrm{mM} \mathrm{KCl}, 3 \mathrm{mM}$ $\mathrm{MgCl}_{2}, 20 \mathrm{mM} \mathrm{DTT}, 0.5 \mathrm{mM}$ dNTPs (each) were heated to $65^{\circ} \mathrm{C}$ for $5 \mathrm{~min}$, then chilled on ice for $1 \mathrm{~min}$. After addition of $1 \mu \mathrm{L}$ (200 U) of Superscript II Reverse Transcriptase (Invitrogen) the reaction was incubated at $54^{\circ} \mathrm{C}$ for $50 \mathrm{~min}$, followed by inactivation at $70^{\circ} \mathrm{C}$ for $15 \mathrm{~min}$. After precipitation the DNA fragments were separated on an $8 \%$ denaturing PAA gel at $2000 \mathrm{~V}$ and visualized by phosphorimaging.

\section{Phosphorylation of rhodopsin by GRK2 and GRK5}

The kinase activity of GRK2 was assessed by phosphorylation of the receptor substrate rhodopsin as described (Winstel et al. 1996). Briefly, phosphorylation reactions were performed in a 
total volume of $50 \mu \mathrm{L}$ of buffer $(10 \mathrm{mM}$ phosphate at $\mathrm{pH} 7.4$, $100 \mathrm{mM} \mathrm{NaCl}, 1 \mathrm{mM}$ EDTA, $10 \mathrm{mM} \mathrm{MgCl}_{2}, 100 \mu \mathrm{M}$ DTT, $20 \mathrm{U}$ SuperaseIn [Ambion] and $75 \mu \mathrm{M}\left[\gamma_{-}{ }^{32} \mathrm{P}\right]$ ATP) containing $50 \mathrm{nM}$ GRK2, $50 \mathrm{nM} \mathrm{G}_{\beta \gamma}$ subunits, $2 \mu \mathrm{M}$ rhodopsin, and the RNA aptamer or control RNA molecules as indicated. Phosphorylation was initiated by light and conducted for $20 \mathrm{~min}$ at room temperature. After SDS-PAGE, receptor phosphorylation was assessed by autoradiography. Similar experiments were performed with GRK5; here GRK2 was replaced with $50 \mathrm{nM}$ GRK5, the phosphate buffer was replaced by a Tris/ $\mathrm{HCl}$ buffer $(\mathrm{pH} 7.4)$, and the $\mathrm{G}_{\beta \gamma}$ subunits were omitted.

\section{Protein kinase assay panel to address aptamer specificity}

The batch of GRK2 for the kinase activity determination was expressed and purified according to standard protocols at GPC Biotech and different from the method described above (to be published elsewhere). For the biochemical assays, full-length GRK2 fused to a Strep tag was used without the addition of $G_{\beta \gamma}$ subunits. GRK2 $\mathrm{IC}_{50}$ and kinase inhibition values were determined using a standard biochemical kinase assay. Maximal kinase activities for GRK2 and for the remaining 14 kinases in the panel were achieved by using individually optimized reaction buffers for each kinase. Since IC $_{50}$ values of ATP competitive inhibitors equal $2 \times K_{i}$ if the ATP concentrations are adjusted to the $K_{m \text { app }}$ (ATP), the $K_{m}$ app (ATP) for each kinase was determined (see Supplementary Table ST1) and used as ATP concentration within each kinase assay (Cheng and Prusoff 1973). Thus, the $\mathrm{IC}_{50}$ and inhibition values between different kinases translate directly into differences in binding affinity.

Assays were performed by mixing substrate, $12.5 \mu \mathrm{Ci} / \mathrm{mL}$ adenosine $5^{\prime}-\left(\gamma-{ }^{33} \mathrm{P}\right)$ triphosphate, and $0.5 \mathrm{U} / \mu \mathrm{L}$ RNasin with indicated concentrations of aptamer and ATP in $40 \mu \mathrm{L}$ reaction buffer. The reaction was started by adding the amount of each kinase preparation (source is indicated in Supplemental Table ST1) that results in $10 \%$ substrate turnover. After 60 min incubation at room temperature the reaction was stopped with $100 \mathrm{mM}$ EDTA and the reaction mixture was transferred to MultiScreen-PH filtration plates (Millipore, MAPHNOB50). Filters were washed three times with $200 \mu \mathrm{L} 0.75 \%$ phosphoric acid each, and filter associated radioactivity was quantified after addition of scintillation liquid (PerkinElmer, 1200-439). In order to calculate the remaining kinase activity, the filter associated radioactivity corresponding to $100 \%$ kinase activity was measured in the absence of aptamer while $0 \%$ kinase activity was determined by adding $100 \mathrm{mM}$ EDTA prior to kinase addition.

\section{Pull-down of endogenous GRK2 with the aptamer $\mathrm{C} 13$}

We washed $45 \times 10^{6}$ HEK 293 cells three times with ice-cold PBS, carefully harvested them with a cell scraper, and collected them by centrifugation at $500 \mathrm{~g}$ for $5 \mathrm{~min}$. The cell pellets were suspended in $900 \mu \mathrm{L}$ of homogenization buffer (PBS supplemented with protease inhibitor mix HP, Serva) and homogenized (Polytron, Kinematica) at $4^{\circ} \mathrm{C}$. After homogenization the suspension was centrifuged for $1 \mathrm{~h}$ at 20,000g. The resultant supernatant was removed and supplemented with $\mathrm{MgCl}_{2}$ and BSA to reach a final concentration of $3 \mathrm{mM}$ and $0.1 \mu \mathrm{g} / \mu \mathrm{L}$, respectively. This cell lysate was then incubated with 200 pmol of either biotinylated C13 or biotinylated control RNA coupled to $1 \mathrm{mg}$ of streptavidin magnetic beads (Invitrogen) for $90 \mathrm{~min}$ at $37^{\circ} \mathrm{C}$. Biotinylated RNA was prepared and coupled to magnetic beads as described previously (Mayer et al. 2007). After incubation, the supernatant was removed and the beads were washed four times with $125 \mu \mathrm{L}$ of washing buffer (PBS/3 mM $\mathrm{MgCl}_{2}$ ). Finally, the beads were suspended in $20 \mu \mathrm{L}$ of SDS-PAGE loading buffer heated for $3 \mathrm{~min}$ at $95^{\circ} \mathrm{C}$, and subsequently analyzed on a SDS-PAGE gel $(12.0 \%)$ followed by Western blot analysis using the GRK2 specific polyclonal antibody C15 (Santa Cruz Biotechnology). Visualization of the corresponding GRK2 band was achieved by ECL chemistry using a HRP-conjugated secondary antibody and a Versa Doc system (BioRad) for luminescence recording.

\section{SUPPLEMENTAL DATA}

Supplemental materials can be obtained from the author via e-mail: gmayer@uni-bonn.de.

\section{ACKNOWLEDGMENTS}

This work was supported by grants from the BMBF (0312708BTIB), the Fonds der Chemischen Industrie, and the DFG (Ma 3442/1-1) to G.M. and M.B. We thank Stefan Müller, Kerstin Hölscher, and Tatjana Freudenreich from GPC Biotech AG for providing expressed and purified GRK2, Rock II, and SRPK1, which were used in the kinase selectivity panel.

Received September 10, 2007; accepted December 7, 2007.

\section{REFERENCES}

Burgstaller, P., Girod, A., and Blind, M. 2002a. Aptamers as tools for target prioritization and lead identification. Drug Discov. Today 7: $1221-1228$.

Burgstaller, P., Jenne, A., and Blind, M. 2002b. Aptamers and aptazymes: Accelerating small molecule drug discovery. Curr. Opin. Drug Discov. Devel. 5: 690-700.

Cheng, Y. and Prusoff, W.H. 1973. Relationship between the inhibition constant (K1) and the concentration of inhibitor which causes 50 per cent inhibition (I50) of an enzymatic reaction. Biochem. Pharmacol. 22: 3099-3108.

Conrad, R., Keranen, L.M., Ellington, A.D., and Newton, A.C. 1994. Isozyme-specific inhibition of protein kinase $\mathrm{C}$ by RNA aptamers. J. Biol. Chem. 269: 32051-32054.

Cox, J.C. and Ellington, A.D. 2001. Automated selection of antiprotein aptamers. Bioorg. Med. Chem. 9: 2525-2531.

Cox, J.C., Hayhurst, A., Hesselberth, J., Bayer, T.S., Georgiou, G., and Ellington, A.D. 2002. Automated selection of aptamers against protein targets translated in vitro: From gene to aptamer. Nucleic Acids Res. 30: e108. doi: 10.1093/nar/gnf107.

Davis, J.H. and Szostak, J.W. 2002. Isolation of high-affinity GTP aptamers from partially structured RNA libraries. Proc. Natl. Acad. Sci. 99: 11616-11621.

Eichmann, T., Lorenz, K., Hoffmann, M., Brockmann, J., Krasel, C., Lohse, M.J., and Quitterer, U. 2003. The amino-terminal domain of G-protein-coupled receptor kinase 2 is a regulatory G $\beta \gamma$ binding site. J. Biol. Chem. 278: 8052-8057.

Ellington, A.D. and Szostak, J.W. 1990. In vitro selection of RNA molecules that bind specific ligands. Nature 346: 818-822.

Famulok, M. and Mayer, G. 2005. Intramers and aptamers: Applications in protein-function analyses and potential for drug screening. ChemBioChem 6: 19-26. 
Fox, T., Coll, J.T., Xie, X., Ford, P.J., Germann, U.A., Porter, M.D., Pazhanisamy, S., Fleming, M.A., Galullo, V., Su, M.S., et al. 1998. A single amino acid substitution makes ERK2 susceptible to pyridinyl imidazole inhibitors of p38 MAP kinase. Protein Sci. 7: 2249-2255.

Giver, L., Bartel, D., Zapp, M., Pawul, A., Green, M., and Ellington, A.D. 1993. Selective optimization of the Rev-binding element of HIV-1. Nucleic Acids Res. 21: 5509-5516. doi: 10.1093/ nar/21.23.5509.

Hafner, M., Schmitz, A., Grune, I., Srivatsan, S.G., Paul, B. Kolanus, W., Quast, T., Kremmer, E., Bauer, I., and Famulok, M. 2006. Inhibition of cytohesins by SecinH3 leads to hepatic insulin resistance. Nature 444: 941-944.

Hamm, J. 1996. Characterization of antibody-binding RNAs selected from structurally constrained libraries. Nucleic Acids Res. 24: 2220-2227. doi: 10.1093/nar/24.12.2220.

Hamm, J., Huber, J., and Luhrmann, R. 1997. Anti-idiotype RNA selected with an anti-nuclear export signal antibody is actively transported in oocytes and inhibits Rev- and cap-dependent RNA export. Proc. Natl. Acad. Sci. 94: 12839-12844.

Hansen, J.L., Theilade, J., Aplin, M., and Sheikh, S.P. 2006. Role of G-protein-coupled receptor kinase 2 in the heart-Do regulatory mechanisms open novel therapeutic perspectives? Trends Cardiovasc. Med. 16: 169-177.

Hartig, J.S., Najafi-Shoushtari, S.H., Grune, I., Yan, A., Ellington, A.D., and Famulok, M. 2002. Protein-dependent ribozymes report molecular interactions in real time. Nat. Biotechnol. 20: 717-722.

Hasbi, A., Allouche, S., Sichel, F., Stanasila, L., Massotte, D., Landemore, G., Polastron, J., and Jauzac, P. 2000. Internalization and recycling of $\delta$-opioid receptor are dependent on a phosphorylation-dephosphorylation mechanism. J. Pharmacol. Exp. Ther. 293: $237-247$.

Hata, J.A. and Koch, W.J. 2003. Phosphorylation of G proteincoupled receptors: GPCR kinases in heart disease. Mol. Interv. 3: 264-272.

Hermann, T. and Patel, D.J. 2000. RNA bulges as architectural and recognition motifs. Structure 8: R47-R54.

Iaccarino, G. and Koch, W.J. 1999. Therapeutic potential of G-protein coupled receptor kinases in the heart. Expert Opin. Investig. Drugs 8: $545-554$.

Kassack, M.U., Hogger, P., Gschwend, D.A., Kameyama, K., Haga, T., Graul, R.C., and Sadee, W. 2000. Molecular modeling of G-protein coupled receptor kinase 2: Docking and biochemical evaluation of inhibitors. AAPS PharmSci 2: E2. doi: 10.1208/ps020102.

Kenski, D.M., Zhang, C., von Zastrow, M., and Shokat, K.M. 2005. Chemical genetic engineering of $\mathrm{G}$ protein-coupled receptor kinase 2. J. Biol. Chem. 280: 35051-35061.

Kim, C.M., Dion, S.B., Onorato, J.J., and Benovic, J.L. 1993. Expression and characterization of two $\beta$-adrenergic receptor kinase isoforms using the baculovirus expression system. Receptor 3: 39-55.

Knight, Z.A. and Shokat, K.M. 2005. Features of selective kinase inhibitors. Chem. Biol. 12: 621-637.

Koch, W.J., Rockman, H.A., Samama, P., Hamilton, R.A., Bond, R.A., Milano, C.A., and Lefkowitz, R.J. 1995. Cardiac function in mice overexpressing the $\beta$-adrenergic receptor kinase or a $\beta$ ARK inhibitor. Science 268: 1350-1353.

Kunapuli, P. and Benovic, J.L. 1993. Cloning and expression of GRK5: A member of the G protein-coupled receptor kinase family. Proc. Natl. Acad. Sci. 90: 5588-5592.

Lefkowitz, R.J. and Shenoy, S.K. 2005. Transduction of receptor signals by $\beta$-arrestins. Science 308: $512-517$.

Lohse, M.J. 1993. Molecular mechanisms of membrane receptor desensitization. Biochim. Biophys. Acta 1179: 171-188.

Lohse, M.J., Lefkowitz, R.J., Caron, M.G., and Benovic, J.L. 1989. Inhibition of $\beta$-adrenergic receptor kinase prevents rapid homologous desensitization of $\beta$ 2-adrenergic receptors. Proc. Natl. Acad. Sci. 86: 3011-3015.
Lohse, M.J., Krasel, C., Winstel, R., and Mayor Jr., F. 1996. G-proteincoupled receptor kinases. Kidney Int. 49: 1047-1052.

Lombardi, M.S., Kavelaars, A., Penela, P., Scholtens, E.J., Roccio, M., Schmidt, R.E., Schedlowski, M., Mayor Jr., F., and Heijnen, C.J. 2002. Oxidative stress decreases $G$ protein-coupled receptor kinase 2 in lymphocytes via a calpain-dependent mechanism. Mol. Pharmacol. 62: 379-388.

Lorenz, K., Lohse, M.J., and Quitterer, U. 2003. Protein kinase C switches the Raf kinase inhibitor from Raf-1 to GRK-2. Nature 426: 574-579.

Lymperopoulos, A., Rengo, G., Funakoshi, H., Eckhart, A.D., and Koch, W.J. 2007. Adrenal GRK2 upregulation mediates sympathetic overdrive in heart failure. Nat. Med. 13: 315-323.

Manning, G., Whyte, D.B., Martinez, R., Hunter, T., and Sudarsanam, S. 2002. The protein kinase complement of the human genome. Science 298: 1912-1934.

Marchese, A., Chen, C., Kim, Y.M., and Benovic, J.L. 2003. The ins and outs of $\mathrm{G}$ protein-coupled receptor trafficking. Trends Biochem. Sci. 28: 369-376.

Mayer, G., Blind, M., Nagel, W., Bohm, T., Knorr, T., Jackson, C.L., Kolanus, W., and Famulok, M. 2001. Controlling small guaninenucleotide-exchange factor function through cytoplasmic RNA intramers. Proc. Natl. Acad. Sci. 98: 4961-4965.

Mayer, G., Raddatz, M.S., Grunwald, J.D., and Famulok, M. 2007. RNA ligands that distinguish metabolite-induced conformations in the TPP riboswitch. Angew. Chem. Int. Ed. Engl. 46: 557560.

Mayor Jr., F., Penela, P., and Ruiz-Gomez, A. 1998. Role of G proteincoupled receptor kinase 2 and arrestins in $\beta$-adrenergic receptor internalization. Trends Cardiovasc. Med. 8: 234-240.

Oppermann, M., Diverse-Pierluissi, M., Drazner, M.H., Dyer, S.L., Freedman, N.J., Peppel, K.C., and Lefkowitz, R.J. 1996. Monoclonal antibodies reveal receptor specificity among G-proteincoupled receptor kinases. Proc. Natl. Acad. Sci. 93: 7649-7654.

Penn, R.B., Parent, J.L., Pronin, A.N., Panettieri Jr., R.A., and Benovic, J.L. 1999. Pharmacological inhibition of protein kinases in intact cells: Antagonism of $\beta$ adrenergic receptor ligand binding by H-89 reveals limitations of usefulness. J. Pharmacol. Exp. Ther. 288: 428-437.

Peppel, K., Boekhoff, I., McDonald, P., Breer, H., Caron, M.G., and Lefkowitz, R.J. 1997. G protein-coupled receptor kinase 3 (GRK3) gene disruption leads to loss of odorant receptor desensitization. J. Biol. Chem. 272: 25425-25428.

Peregrin, S., Jurado-Pueyo, M., Campos, P.M., Sanz-Moreno, V., Ruiz-Gomez, A., Crespo, P., Mayor Jr., F., and Murga, C. 2006. Phosphorylation of p38 by GRK2 at the docking groove unveils a novel mechanism for inactivating p38MAPK. Curr. Biol. 16: 2042 2047.

Petrofski, J.A. and Koch, W.J. 2003. The $\beta$-adrenergic receptor kinase in heart failure. J. Mol. Cell. Cardiol. 35: 1167-1174.

Pitcher, J.A., Freedman, N.J., and Lefkowitz, R.J. 1998. G proteincoupled receptor kinases. Annu. Rev. Biochem. 67: 653-692.

Premont, R.T. and Gainetdinov, R.R. 2007. Physiological roles of G protein-coupled receptor kinases and arrestins. Annu. Rev. Physiol. 69: 511-534.

Premont, R.T., Inglese, J., and Lefkowitz, R.J. 1995. Protein kinases that phosphorylate activated G protein-coupled receptors. FASEB J. 9: $175-182$.

Premont, R.T., Macrae, A.D., Aparicio, S.A., Kendall, H.E., Welch, J.E., and Lefkowitz, R.J. 1999. The GRK4 subfamily of G protein-coupled receptor kinases. Alternative splicing, gene organization, and sequence conservation. J. Biol. Chem. 274: 29381-29389.

Rentmeister, A., Mayer, G., Kuhn, N., and Famulok, M. 2007. Conformational changes in the expression domain of the Escherichia coli thiM riboswitch. Nucleic Acids Res. 35: 3713-3722.

Ribas, C., Penela, P., Murga, C., Salcedo, A., Garcia-Hoz, C., JuradoPueyo, M., Aymerich, I., and Mayor Jr., F. 2007. The G proteincoupled receptor kinase (GRK) interactome: Role of GRKs in GPCR regulation and signaling. Biochim. Biophys. Acta 1768: 913-922. 
Rockman, H.A., Koch, W.J., and Lefkowitz, R.J. 2002. Seven-transmembrane-spanning receptors and heart function. Nature 415: 206-212.

Seiwert, S.D., Stines Nahreini, T., Aigner, S., Ahn, N.G., and Uhlenbeck, O.C. 2000. RNA aptamers as pathway-specific MAP kinase inhibitors. Chem. Biol. 7: 833-843.

Tesmer, V.M., Kawano, T., Shankaranarayanan, A., Kozasa, T., and Tesmer, J.J. 2005. Snapshot of activated G proteins at the mem-

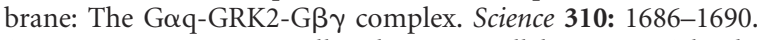

Theis, M.G., Knorre, A., Kellersch, B., Moelleken, J., Wieland, F., Kolanus, W., and Famulok, M. 2004. Discriminatory aptamer reveals serum response element transcription regulated by cytohesin-2. Proc. Natl. Acad. Sci. 101: 11221-11226.

Tuerk, C. and Gold, L. 1990. Systematic evolution of ligands by exponential enrichment: RNA ligands to bacteriophage T4 DNA polymerase. Science 249: 505-510.

Ungerer, M., Bohm, M., Elce, J.S., Erdmann, E., and Lohse, M.J. 1993. Altered expression of $\beta$-adrenergic receptor kinase and $\beta$ 1-adrenergic receptors in the failing human heart. Circulation 87: 454-463.

Ungerer, M., Parruti, G., Bohm, M., Puzicha, M., DeBlasi, A., Erdmann, E., and Lohse, M.J. 1994. Expression of $\beta$-arrestins and $\beta$-adrenergic receptor kinases in the failing human heart. Circ. Res. 74: 206-213.
Usui, I., Imamura, T., Satoh, H., Huang, J., Babendure, J.L., Hupfeld, C.J., and Olefsky, J.M. 2004. GRK2 is an endogenous protein inhibitor of the insulin signaling pathway for glucose transport stimulation. EMBO J. 23: 2821-2829.

Usui, I., Imamura, T., Babendure, J.L., Satoh, H., Lu, J.C., Hupfeld, C.J., and Olefsky, J.M. 2005. G protein-coupled receptor kinase 2 mediates endothelin-1-induced insulin resistance via the inhibition of both $\mathrm{G} \alpha \mathrm{q} / 11$ and insulin receptor substrate-1 pathways in 3T3-L1 adipocytes. Mol. Endocrinol. 19: $2760-2768$.

Vroon, A., Heijnen, C.J., Lombardi, M.S., Cobelens, P.M., Mayor Jr., F., Caron, M.G., and Kavelaars, A. 2004. Reduced GRK2 level in $\mathrm{T}$ cells potentiates chemotaxis and signaling in response to CCL4. J. Leukoc. Biol. 75: 901-909.

Wilson, D.S. and Szostak, J.W. 1999. In vitro selection of functional nucleic acids. Annu. Rev. Biochem. 68: 611-647.

Winstel, R., Freund, S., Krasel, C., Hoppe, E., and Lohse, M.J. 1996. Protein kinase cross-talk: Membrane targeting of the $\beta$-adrenergic receptor kinase by protein kinase C. Proc. Natl. Acad. Sci. 93: 2105-2109.

Winstel, R., Ihlenfeldt, H.G., Jung, G., Krasel, C., and Lohse, M.J. 2005. Peptide inhibitors of $G$ protein-coupled receptor kinases. Biochem. Pharmacol. 70: 1001-1008. 

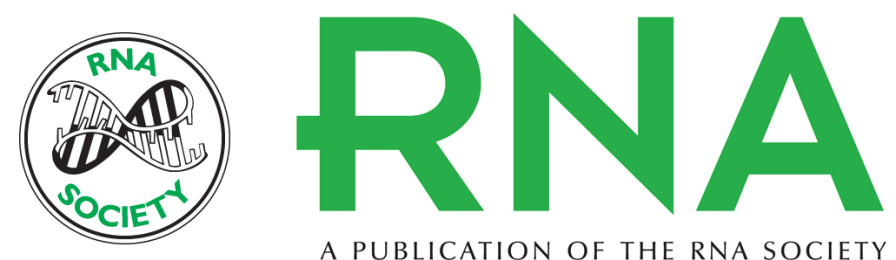

A PUBLICATION OF THE RNA SOCIETY

\section{An RNA molecule that specifically inhibits G-protein-coupled receptor kinase 2 in vitro}

Günter Mayer, Bernhard Wulffen, Christian Huber, et al.

RNA 2008 14: 524-534

References This article cites 63 articles, 23 of which can be accessed free at: http://rnajournal.cshlp.org/content/14/3/524.full.html\#ref-list-1

\section{License}

Email Alerting Receive free email alerts when new articles cite this article - sign up in the box at the Service top right corner of the article or click here. 